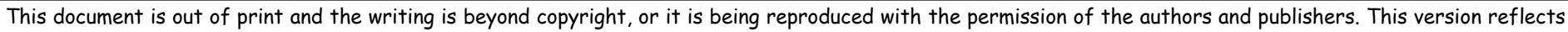

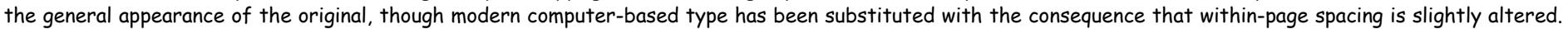

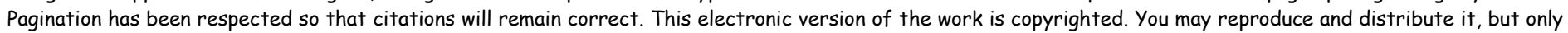
for free and only with this notice intact. Related material is available at our web site.

\title{
Rhyythmichights.eom
}

OFred Collopy 2001.

\section{Instruments to Perform Color-Music: Two Centuries of Technological Experimentation}

\section{Kenneth Peacock}

\begin{abstract}
In our multi-media age, low-cost technology has facilitated the creation of convincing artistic works that combine music and colored light. The most elusive aspect of this art, historically termed 'color-music', has been the light-projection instrument. Attempts to develop such a device date from the eighteenth century and, since that time, many machines have been proposed. The author discusses the most significant of these instruments which, in many cases, were developed by experimenters working in isolation.
\end{abstract}

\section{INTRODUCTION}

Over 100 years ago, Walter Pater remarked in one of his essays on the Renaissance spirit that, "all art constantly aspires towards the condition of music" [1]. The enviable position of music, he argued, was that the means of artistic expression allowed complete integration of form and content-an impossible state for the less abstract arts. Pater could not, of course, have anticipated the artistic direction of painters like Vasily Kandinsky, who with others early in the twentieth century, used analogues of music to develop a style of painting in which pure color and line articulated abstract, non-objective themes. Nor could Pater have anticipated the explosion of interest in abstract kinetic art which has characterized our century. And today, widespread acceptance of technology as an indispensable tool for artists has tended to blur the lines of distinction between music and the sister arts of painting and sculpture [2].

Many Leonardo readers would agree that musical connotations are intended by artists who have referred to their paintings as 'compositions'. Of course this term is not tied exclusively to music, but composers and other musicians are generally accustomed to using the word when discussing musical works. More specific connections to music can be seen in such paintings as Mondrian's Broadway Boogie-Woogie, Kupka's Fugue in Red and Blue, or Symphony in Violet by Albert Gleizes. Actually, the issue of musical means of expression employed by artists in other fields is much older than one

Kenneth Peacock (musicologist, fine arts educator), Eastern Connecticut State University, Windham, CT 06226, U.S.A.

Received 11 August 1987.

(C) 1988 ISAST

Pergamon Press plc.

Printed in Great Britain.

0024-094X/88 \$3.00+0.00

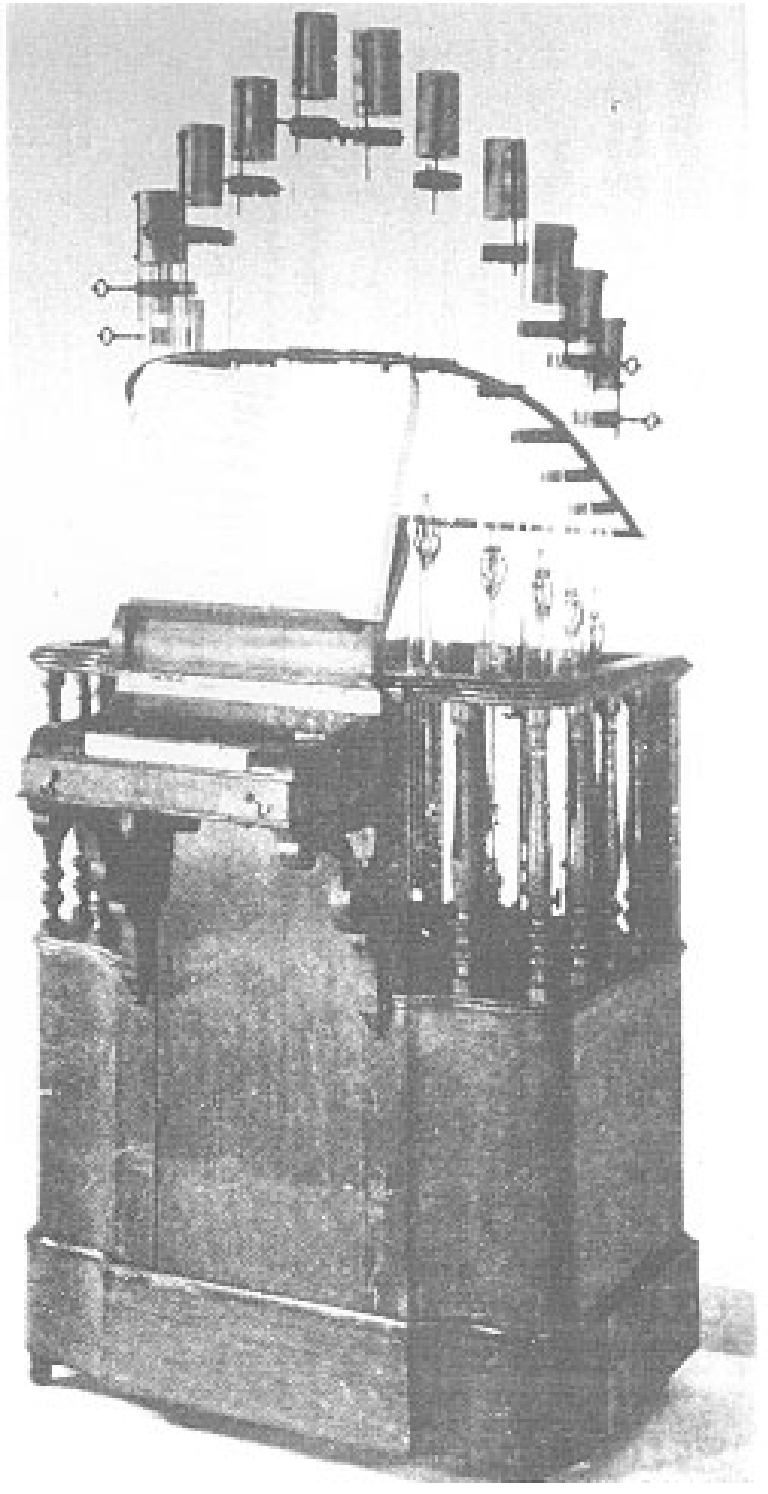

Fig. 1. Frederick Kastner's Pyrophone (ca. 1870). Ignited gas jets opening into crystal tubes were controlled from the keyboard. In addition to a visual display, the instrument was reputed to produce sounds similar to the human voice, piano or full orchestra. 
might at first suspect. Music has frequently been associated with the concept of color since before the time of Aristotle, and the ancient philosophers believed "harmony to be the union of varied colored things" [3].

'Color in music' has had many meanings. At different times, the term has described purity of tone, instrumental quality, melodic ornamentation or even literal color in manuscripts. For example, in the eleventh century, red and yellow lines indicated the pitches $\mathrm{F}$ and $\mathrm{C}$ before the development of musical staves. 'Color' has a specific meaning in the fourteenth-century isorhythmic motet, and the term 'coloratura' has different connotations in the music of the sixteenth through nineteenth centuries. Comparisons between music and color have seemed a most natural human activity, and the topic has been of interest to writers in many fields.

In 1690, the English philosopher John Locke published An Essay Concerning Human Understanding. Locke's work contained an incidental statement that a blind man had claimed the sound of a trumpet to be like the color scarlet. This prompted heated international discussions during the eighteenth and nineteenth centuries concerning the possibility of correspondence between light and sound. Anthony Cooper (the third Earl of

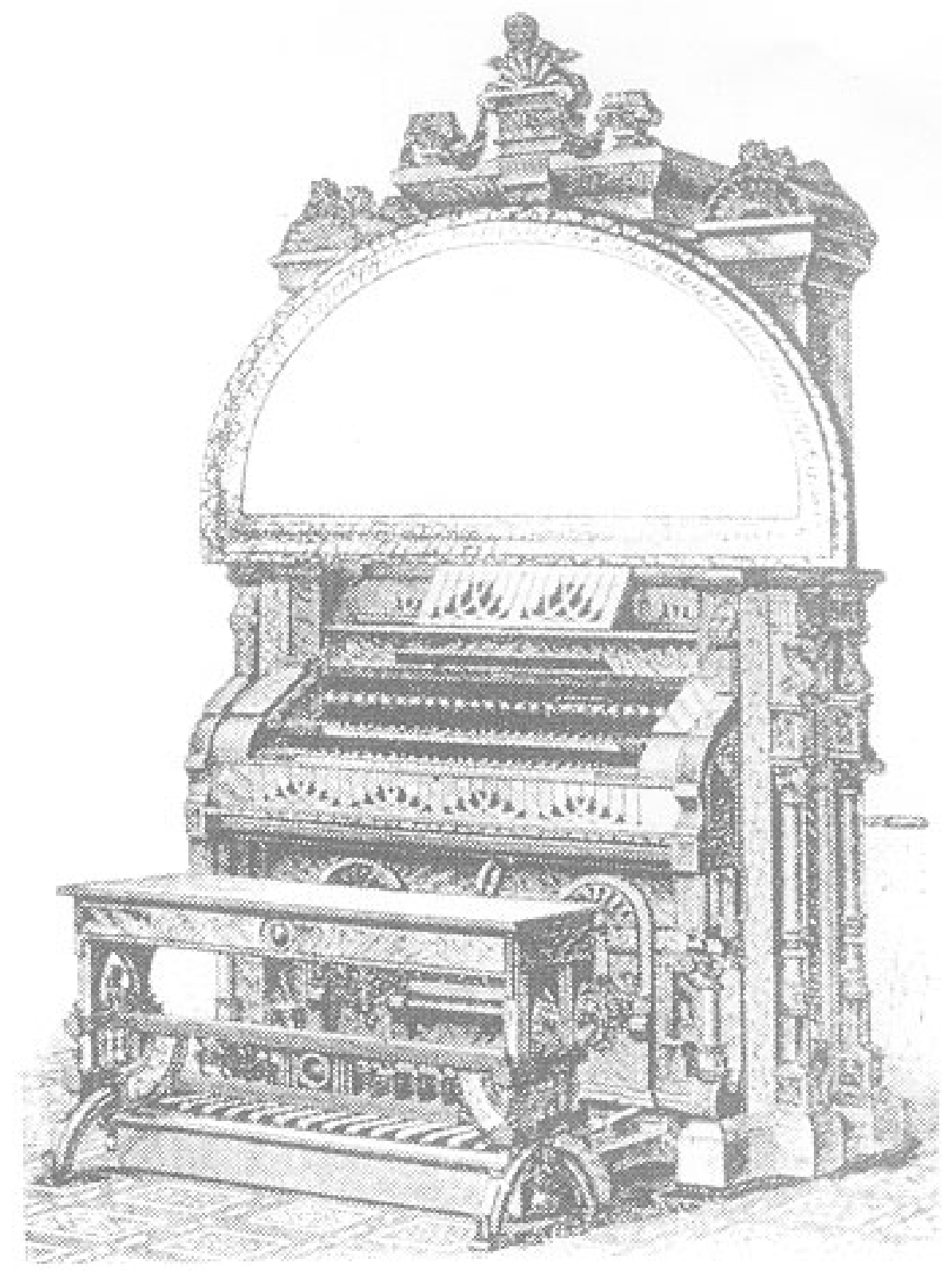

Fig. 2. Bainbridge Bishop's device for 'painting music' (1877). The light producing apparatus was placed on top of a normal organ, and a system of levers and shutters allowed colored light to be blended on the screen while music was performed. P.T. Barnum had one of these at home. It could be considered similar to today's 'color-organs', which are connected to home stereos.

Shaftesbury), Henry Fielding, Adam Smith and Erasmus Darwin argued the issue in England, while Louis-Bertrand Castel, Mme de Stael and others considered it on the opposite side of the Channel. Understanding the nature of light was perhaps as important to the debate as the development of an art form that unified different modes of expression.

Both sides of the question were articulated by Goethe, who first embraced but later rejected the idea of an analogy between musical tone and colored light [4]. Such analogies were encouraged by the new theory that both sound and light were the result of similar vibrations of a medium. Air provided a medium for sound, and 'luminiferous ether', thought to pervade the universe, was the substance through which light could travel. It was postulated that only the rate of vibration was responsible for the nature of the effects produced in each case. This idea gained support because coincidental mathematical similarities in vibration ratios are seen if one end of the visible spectrum is compared to the other and, in turn, compared to vibrational relationships within a musical octave. For example, the vibrational frequency of violet is approximately twice that of red. And some believed that if the sound of middle-C could be raised by 40 octaves, one would see red light [5].

Sir Isaac Newton was the first to observe a correspondence between the proportionate width of the seven prismatic rays and the string lengths required to produce the musical scale D, E, F, G, A, B, C. Several nineteenth-century scientists cautioned against oversimplifying the analogy, but the belief that light and sound were physically similar continued to appear in textbooks published after the first third of our century. The existence of luminiferous and electromagnetic ether was disproven by the Michelson-Morley experiment of 1887; yet over 20 years later, one discussion of the possibilities of combining color and music attempted to "sum up the scientific side" by stating:

\section{In a general way it seems to be indicated that harmonic colours are the results of vibratory effects upon the eye of multiples of like measurements, thus fulfilling exactly the analogy according to which harmonious effects are produced upon the ear [6].}

There always has been a considerable lag time before artists have incorporated new scientific findings into their work, but in the case of what was termed 'color-music', scientific agreement seemed an unnecessary prerequisite to the development of the new art form. One consequence 


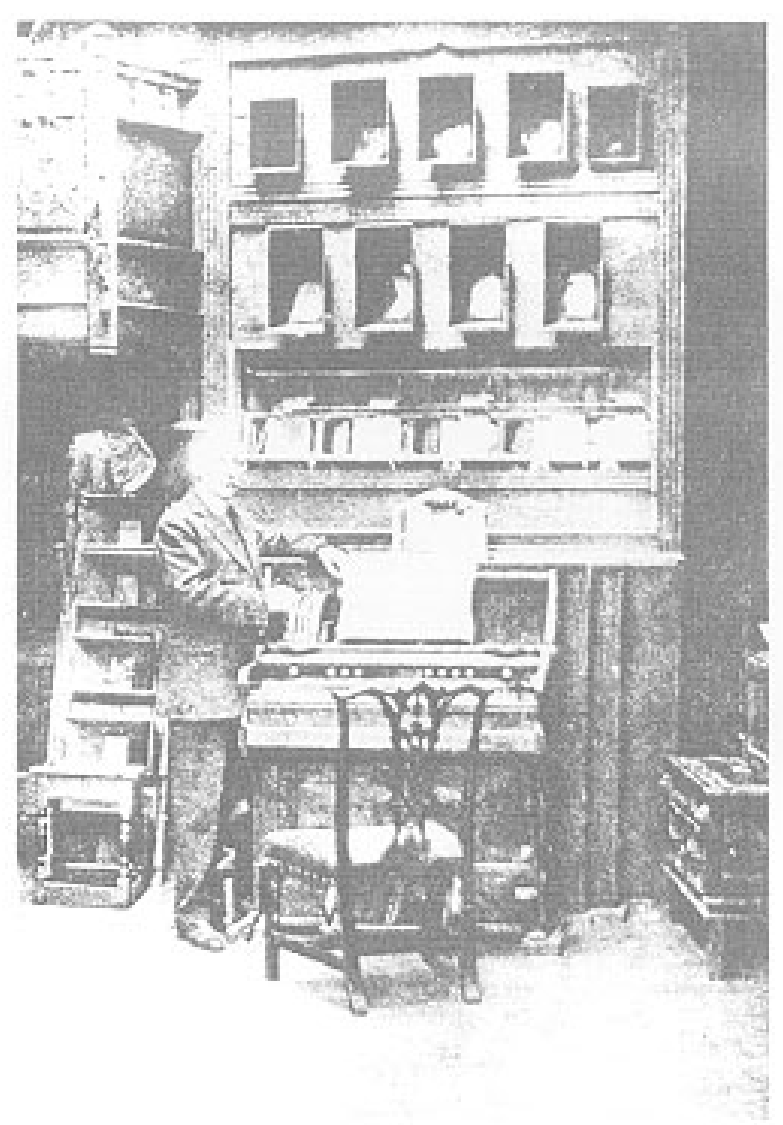

Fig. 3. Alexander Rimington with his Colour-Organ (1893). This instrument produced no sound, but trackers from the five-octave keyboard were connected to lens diaphragms and filters for 14 arc lamps.

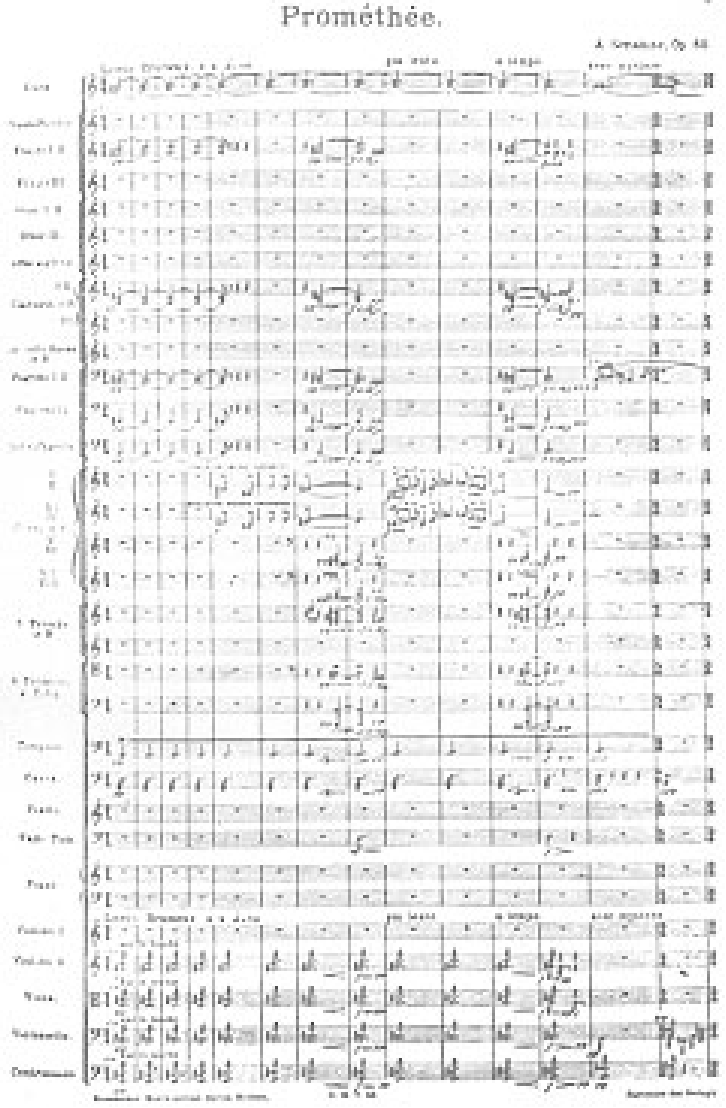

Fig. 4. First page of Alexander Scriabin's Prometheus, the Poem of Fire (1911). The Tastiera per luce part for colored light appears at the top of the score. Here, the upper voice $(\mathrm{A})$ indicates the color to be projected (green) while simultaneously showing the root of the famous six-note 'mystic' chord played by the orchestra. (Used by permission of Boosey and Hawkes Inc., copyright owners.) of the lively debate over correspondence between colored light and sound was widespread interest in a viable colortransmission instrument that could be operated from a musical keyboard. Early proposals date from shortly after the initiation of the controversy.

\section{THE EIGHTEENTH-CENTURY CLAVECIN OCULAIRE}

A French Jesuit named Louis-Bertrand Castel (1688-1757) was the first to respond with a proposal for the performance of color-music. Well known during his lifetime, Castel was considered an eminent mathematician, but his writings also show an interest in aesthetics. His work attracted attention in England where he was made a Fellow of the Royal Society-an honor probably bestowed because of his reputation in mathematics, not because of his clavecin oculaire.

Castel wrote two major essays concerning a 'harpsichord for eyes'. The first was in the form of an extended letter (dated 20 February 1725) published in the November 1725 issue of Mercure de France. A development of those ideas appeared in Mémoires de Trévoux (1735) under the title "Nouvelles experiences d'optique et d'acoustique". It was translated into German and annotated by the composer Georg Philipp Telemann who had it published in quarto. This second essay was also translated into English in 1757 by an anonymous student who apparently had assisted Castel with some of his experiments [7]. The idea for a clavecin oculaire was stimulated by writings of Athanasius Kircher (1601-1680), who had experimented with the magic lantern - an invention that became the slide projector. In his first article on the subject, Castel asked:

\footnotetext{
Why not make ocular as well as auricular harpsichords? It is again to our good friend [Kircher] that I owe the birth of such a delightful idea. Two years ago I was reading his Musurgia: there I found that if during a beautiful concert we could see the air which is
}

agitated by all the various tremors of the voice and instruments, we would be astonished to see it sown with the most vivid colors [8].

Apparently Castel considered himself a philosopher rather than a technician, and he originally intended only to theorize about the feasibility of making color-instruments, but his ideas encountered skepticism. This prompted him to construct a model which was completed in 1734. It is not clear whether he wanted his clavecin oculaire to accompany sound or to substitute colors for sound according to his particular system of correspondence, which was influenced by the discoveries of Newton.

Newton had described important prismatic experiments in papers he read before the Royal Society, and this information was later published in his Opticks (1704). Reflecting a preoccupation with systems of order, which characterized philosophical thinking during the Age of Reason, Newton considered the fundamental order of the spectrum, i.e. red 
through violet, to be equivalent to the 'natural' order of tones from C to B. Castel, however, believed that the color blue was analogous to $\mathrm{C}$, and he modified Newton's distribution of the visible spectrum. Table 1 indicates the colors controlled by the harpsichord keyboard of Castel's clavecin oculaire.

Describing how one should play his instrument, Castel wrote:

Do you want blue? Put your finger on the first key to the left. Do you want the same only I degree lighter? Touch the 8 th note. If you want it 2 degrees, or 3 degrees..., touch the 15th, or 22nd, or 29th, or the last to the right. If you want blue-green, touch the first black to the left. Do you want red, and which red? Crimson-red? That is the 4th black. You have only... to know your clavier and know that blue is $\mathrm{C}$ and red is $\mathrm{G}$ etc. This you can acquire with three days practice [9].

This description clearly implies an instrument of five octaves. In his Optique des couleurs, Castel proposed to implement his color system via harpsichords constructed with 12 octaves! He believed the limits of aural perception encompassed 12 octaves (from 16 to over 65,000 cycles

Table 1. Keyboard colors proposed by Castel for his clavecin oculaire (18th century)

\begin{tabular}{llll}
\hline C & -Blue & F-sharp & - Orange \\
C-sharp & - Celadon (blue-green) & G & - Red \\
D & - Green & A-flat & - Crimson \\
E-flat & - Olive green & A & - Violet \\
E & - Yellow & B-flat & - Agate \\
F & - Apricot (yellow-orange) & B & - Indigo \\
\hline
\end{tabular}

per second), and since colors were analogous to sounds, the arrangement of color tints should follow a similar pattern. Thus by mixing various amounts of white and black into each of the 12 pigments, 144 different colors would be obtained for the clavecin oculaire [10]. Castel had first attempted to use prisms for his instrument, but the colors obtained by refraction of light probably were not of sufficient luminosity. He abandoned this method. Later experiments were conducted with candles, mirrors and colored papers. Each key operated one of the 144 cylindrical candle covers, allowing light to shine through colored paper when the flame was exposed.

Telemann reported that Castel was encouraged by his friends to seek practical realization of his plans, and that "without the aid of craftsmen he [had] nearly finished [the project]" [11]. This statement, though apparently based on Castel's own remarks, is misleading because no full-sized clavecin pour les yeux was ever built. Albert Wellek concluded, after investigating all of the documents pertaining to the issue, "Above all there can be no doubt that Castel's construction was certainly begun, but by no means did this lead to a fortunate termination" [12]. There also seems to be little evidence that the model of Castel's instrument performed according to his expectations. A copy of the 1757 brochure entitled Explanation of the Ocular Harpsichord Upon Shew to the Public (the anonymous translation of Castel's essay
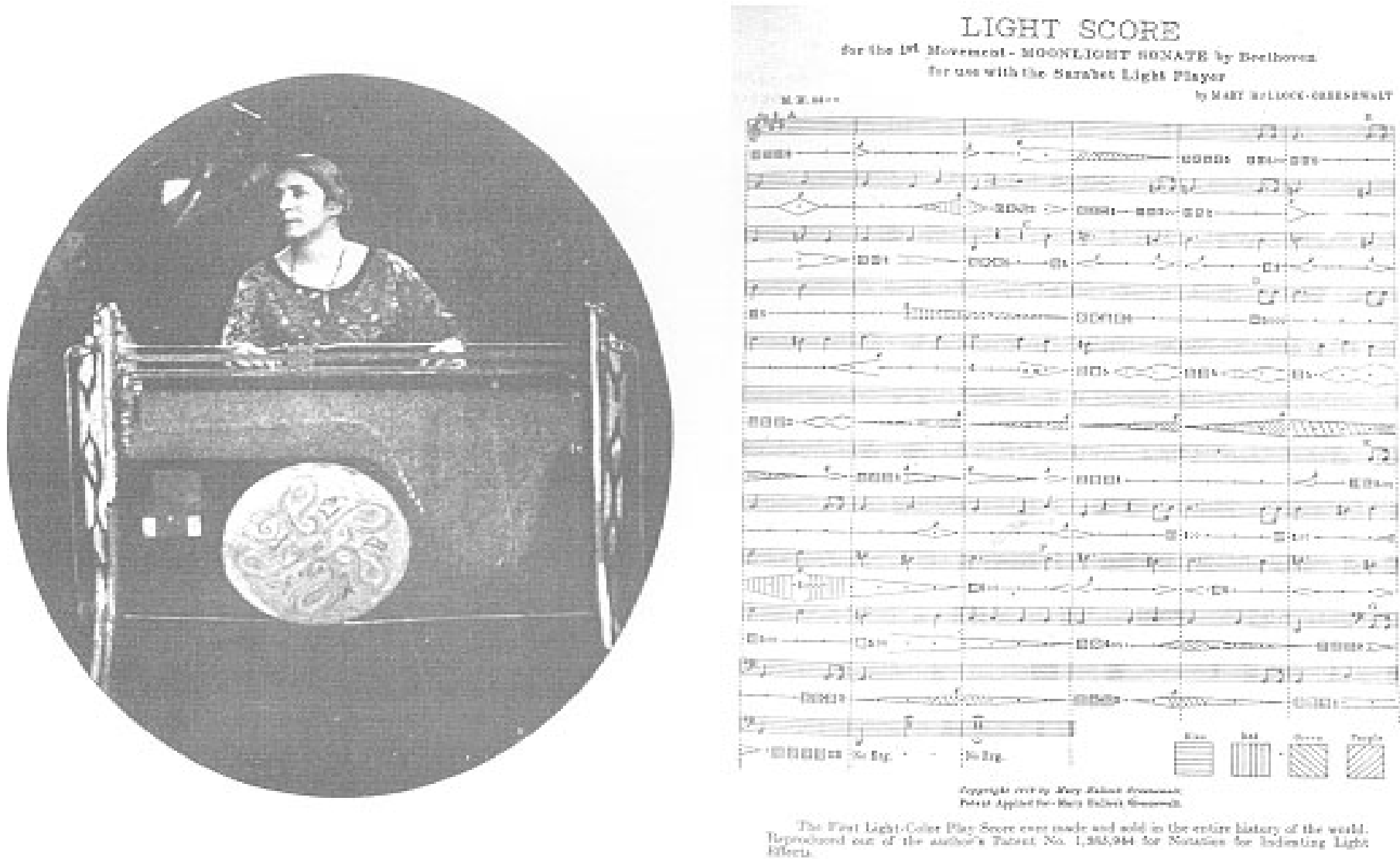

Fig. 5. (a) Mary Hallock-Greenewalt at the console of her Sarabet (1919). A sliding rheostat controlled the reflection of seven coloured lights onto a monochromatic background. (b) Hallock-Greenewalt's patented system of light notation indicated subtle variations of luminosity, which she considered as parallel to nuances in musical expression. This Beethoven composition was originally for solo piano. 
of 1735) is located in the British Museum. The envelope that contains the pamphlet has a handwritten note signed by M. Low, the first owner:

I was admitted among a select party to a sight of [this instrument] at the Great Concert Room in Soho Square; but to a sight of the instrument only, for nothing was then performed nor afterwards, as ever I heard, neither did I ever know why [13].

In spite of this, there is no question that the interesting experiments of Father Castel were directly responsible for the development of other theories and instruments in the first half of the nineteenth century. Although these yielded no lasting results, they led to later innovations that initiated our own audiovisual age.

\section{NINETEENTH-CENTURY INSTRUMENTS}

Castel had proposed a color-music technology employing diffuse reflection of light from pigment. In 1789, Erasmus Darwin (grandfather of the renowned naturalist) suggested that the newly invented Argand oil lamps might be used to produce visible music by projecting strong light through 'coloured glasses'. This is probably the basis for the instrument described by D.D. Jameson in his pamphlet Colour-Music (1844).

Jameson specified a system of notation for the new art form and also described his apparatus in some detail. A darkened room in which the walls were lined with reflecting tin plates provided the setting for his 'colourific exhibition'. In one wall, 12 round apertures revealed glass containers filled with liquids of various colors corresponding to the chromatic scale - "the bottles seen in the windows of druggists' shops can be used for this purpose". These acted as filters for light projected from behind the wall. Moveable covers were activated by a seven-octave keyboard, and each was raised a specific height depending on which octave was chosen.

Another intriguing instrument was constructed in England between 1869 and 1873 by Frederick Kastner. This was a type of gas organ which the inventor called a Pyrophone. He undoubtedly developed his idea after hearing the hissing sound made by gas jets, which were commonly used for interior lighting before electricity. Supposedly, his apparatus produced sounds similar to the human voice, piano or full orchestra. Cylindrical filters covered ignited gas jets (Fig. 1). Kastner later extended the

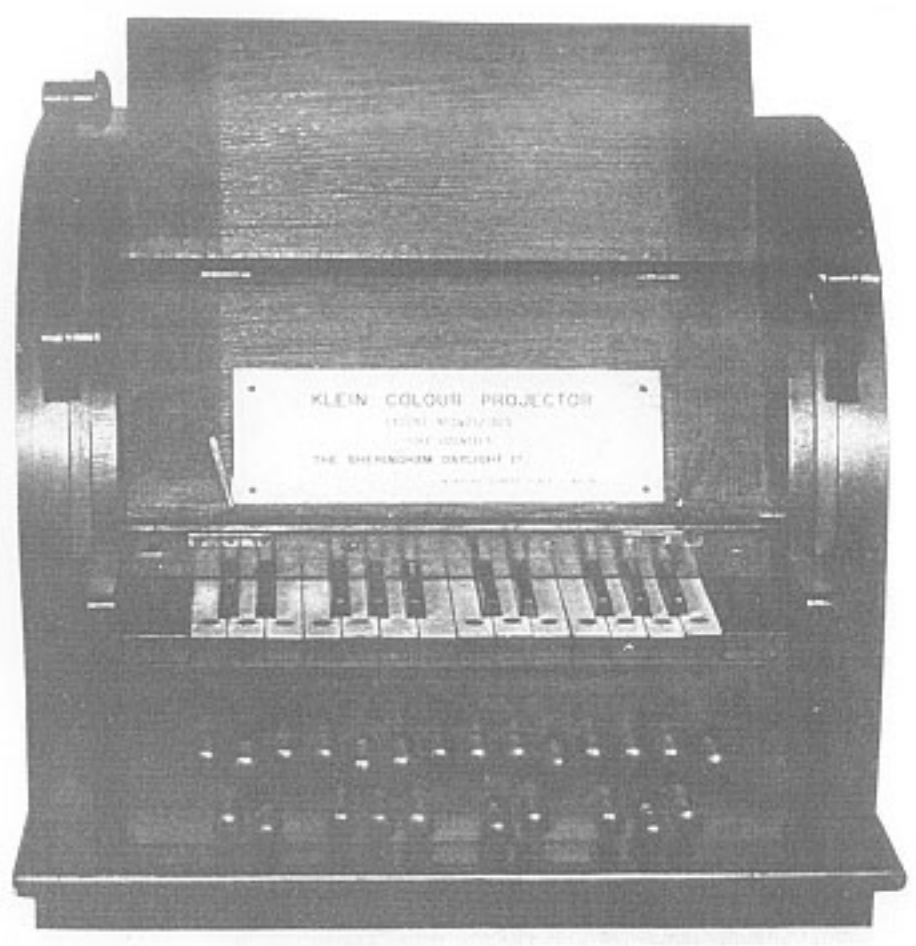

Fig. 6. The two-octave controller of Adrian Klein's color projector for stage lighting (1920). This instrument demonstrated Klein's color theories in which the visible spectrum was logarithmically divided.

possibilities for the visual portion of his experiments after electricity became available. A device he termed the 'singing lamp' was essentially,

a sort of pyrophone with thirteen branches, all decorated with foliage and furnished with burners containing several gas jets, which opened into crystal tubes. These burners were brought into play electrically, through an invisible wire that connected to a keyboard in a neighbouring room or street-or indeed another part of the town [14].

In the United States in 1877, Bainbridge Bishop, who had been interested in the concept of 'painting music', constructed a machine that was to be placed on top of a home organ (Fig. 2). A system of levers and shutters allowed colored light to be blended on a small screen at the same time as a piece of music was being performed on the organ. Sunlight was first used as the source of illumination, but later an electric arc was placed behind the colored glass. Bishop's invention attracted P.T. Barnum's attention, and the famous showman later had one of the instruments installed in his Connecticut residence [15].
A bold proposal was advanced by William Schooling in an article published in The Nineteenth Century (July 1895). Although there is no evidence that an instrument actually was built, his suggestion to use vacuum tubes of various shapes is remarkable. Contacts on a keyboard would electrically activate individual tubes, and the intensity of illumination could be varied with a pedal to alter levels of current. It is not difficult to see this concept as a forerunner of present-day computer-controlled artistic or commercial lighting systems. They have become so prevalent that we now take them for granted.

The best-known color instrument of the last century was patented in 1893 by Alexander Wallace Rimington (1854-1918). The inventor, a professor of fine arts at Queen's College in London, called his apparatus the Colour-Organ, and this name has become the generic term for all such devices designed to project colored light. Rimington described his instrument and the color theories upon which it was based in a book entitled Colour-Music: The Art of Mobile Colour (1911).

Rimington was convinced that physical analogies of some kind existed between 
sound and color. In his book, he repeatedly compared the two phenomena, claiming that both "are due to vibrations which stimulate the optic and aural nerve respectively". Much space was devoted in the appendix to supporting viewpoints. He did admit, however, that the analogy was along broad lines and that the correctness of his own theory was open to question. Rather than attempting to show an exact parallel between vibration frequencies of light and sound, he divided the spectrum into intervals of the same proportions as occur in a musical octave. Thus the ratio between two light waves approximated that for a corresponding interval in sound. Rimington's color scale is shown in Table 2 [16]. Each octave contained the same colors, and registral placement of colors was directly proportional to saturation, i.e. higher octaves contained more white light.

The Colour-Organ stood over 10 feet high arc lamps and many filters varnished with aniline dye. It also required a power supply capable of providing 150 amps. The five-octave keyboard resembled that of an ordinary organ and was connected by a series of trackers to a corresponding set of diaphragms in front of special lenses. Stops were furnished to control the three variables of color perception: hue, luminosity, and chroma (color purity). One stop allowed the performer to spread the spectrum band over the entire keyboard instead of over one octave - proof of Rimington's flexible attitude concerning the analogy between particular colors and tones.
Table 2. Colors produced by the keyboard of Rimington's Colour-Organ (1893)

\begin{tabular}{llll}
\hline C & -Deep red & F-sharp & - Green \\
C-sharp & - Crimson & G & - Bluish green \\
D & - Orange-crimson & A-flat & - Blue-green \\
E-flat & - Orange & A & - Indigo \\
E & -Yellow & B-flat & -Deep blue \\
F & -Yellow-green & B & -Violet \\
\hline
\end{tabular}
(Fig. 3). A complex apparatus, it employed 14

Like all earlier mechanisms (with the exception of Kastner's Pyrophone), Rimington's instrument was not capable of producing any sounds. He did recommend, however, that compositions played in color be performed simultaneously on sound-producing instruments for increased enjoyment of the color. No new notational system was needed because musical compositions were played on the keyboard in a normal manner and thereby 'translated' into colored light.

Rimington's efforts attracted considerable attention. According to a report in the Musical Courier (8 June 1985), Sir Arthur Sullivan improvised on the Colour-Organ shortly after its completion. However, he played with his eyes closed. On 6 June 1895, Rimington presented a private lecture-demonstration in London which was attended by over 1,000 people. His Colour-Organ was accompanied by a piano, a normal sound-producing organ and a full orchestra. It is interesting that this is the same instrumentation called for in Alexander Scriabin's famous 1911 colorsymphony, Prometheus (Fig. 4). Scriabin, who probably knew of Rimington's

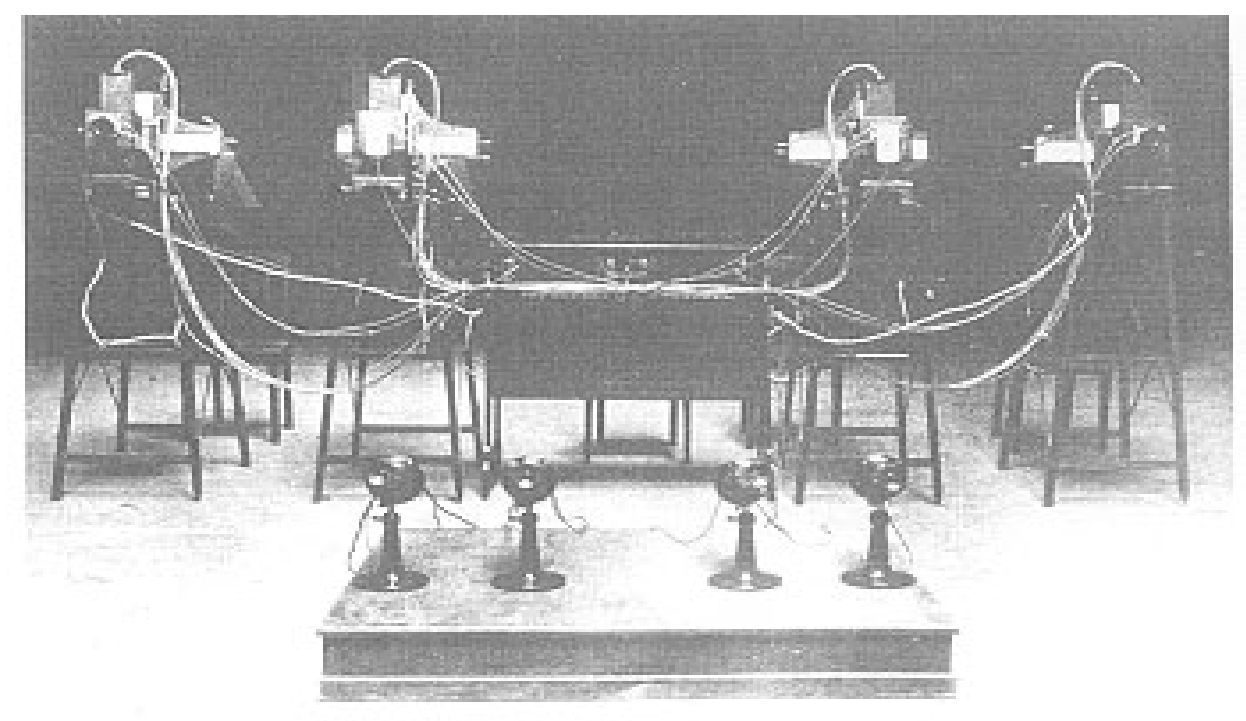

Fig. 7. Alexander Laszlo's Sonchromatoscopewas introduced at the 1925 Music-Art Festival at Kiel, Germany. Laszlo published a series of preludes for piano and colored light which employed his own system of notation. work, was the first composer to include a part for projected light-his Tastiera per luce-in a score for orchestra [17]. Four subsequent public concerts were given by Rimington in 1895 in which compositions by Wagner, Chopin, Bach, and Dvorak were performed. There were apparently no other presentations until after Rimington published his book in 1911. Sir Henry Wood contacted the inventor in 1914 concerning a proposed realization of the color part in Scriabin's Prometheus, but World War I prevented implementation of the performance, and another attempt to produce this work with colored lighting was not undertaken in England until 1972 [18].

\section{COLOR INSTRUMENTS DEVELOPED AFTER SCRIABIN'S PROMETHEUS}

Many reviewers of Scriabin's colorsymphony have remarked that the first performance of Prometheus, the Poem of Fire, given in Moscow on 15 March 1911, did not include color realization because the machine to perform the lighting part would not operate. Additional information has not been located, but it seems reasonable to assume that if such a machine did exist, it was probably a larger version of the model constructed by Scriabin's friend Mozer. Apparently no expense was spared for the original production of Prometheus as Serge Koussevitsky gave the work an unprecedented nine rehearsals. It is puzzling, if such an instrument was available, that no attempt was made to use this Tastiera per luce in subsequent performances.

The first public presentation of Scriabin's symphony accompanied by colored lighting (20 March 1915) was in Carnegie Hall. According to a report published in the New York Times the day before the performance, Modest Altschuler had contacted the president of the Electrical Testing Laboratories for assistance in realizing the color portion of Prometheus. Preston S. Millar, a specialist in electrical lighting, was then assigned to supervise construction of a color-projection instrument later named the Chromola.

Two versions of the Chromola were 
built over a period of 3 months, and, according to the New York Times article "thousands of dollars were spent before the project was completed". Special lamps were manufactured by General Electric as the instrument projected 12 separate colors. It was operated from a keyboard with 15 keys - the extra keys repeated the first three colors of the scale. When key contacts were closed, a low-voltage DC circuit activated the 110-volt AC circuit to one of the projecting lamps. Unlike previous devices, this machine was not built to demonstrate a particular association between color and sound; it was intended solely for performances of Prometheus.

A problem was quickly encountered because Scriabin gave no indication for the colors he considered parallel to the musical notation of the Luce part. Six years after the first effort to present Prometheus with coordinated light, colorist Mathew Luckiesh wrote:

Some of those responsible for the rendition of this music, with color accompaniment, had, at different times previous to the final presentation, accepted both the Rimington scale and Scriabine's code (the latter having been discovered later in a musical journal published ... in London) as being properly related to the music) [19].

Altschuler's Carnegie Hall production of Prometheus generally met with disfavor. One critic dismissed the colored lights, which were flashed onto a small white screen, as a "pretty poppy show". For various reasons, the Chromola was considered one of the instruments of the orchestra rather than equal in effect to the combined instrumental and choral forces as Scriabin intended. Also the audience evidently expected more. Technical problems contributed to difficulties, and not enough time was allowed to establish an artistic setting. Inappropriate theater facilities further diminished the possibility of a successful color realization.

A report in the New York Times Magazine (28 March 1915) indicated that an apparently successful private presentation of the color symphony accompanied by the Chromola took place at the Century Theater "about February 10th". Members of the distinguished audience included Isadora Duncan, Anna Pavlova and Mischa Elman. On that occasion, Millar (the inventor of the Chromola) was quoted by the New York Times as saying:

It was my dream to utilize an entire theatrical stage, hanging parallel curtains of thin diaphanous gauze from the proscenium, back to the rear wall of the theater, thus giving the light depth and
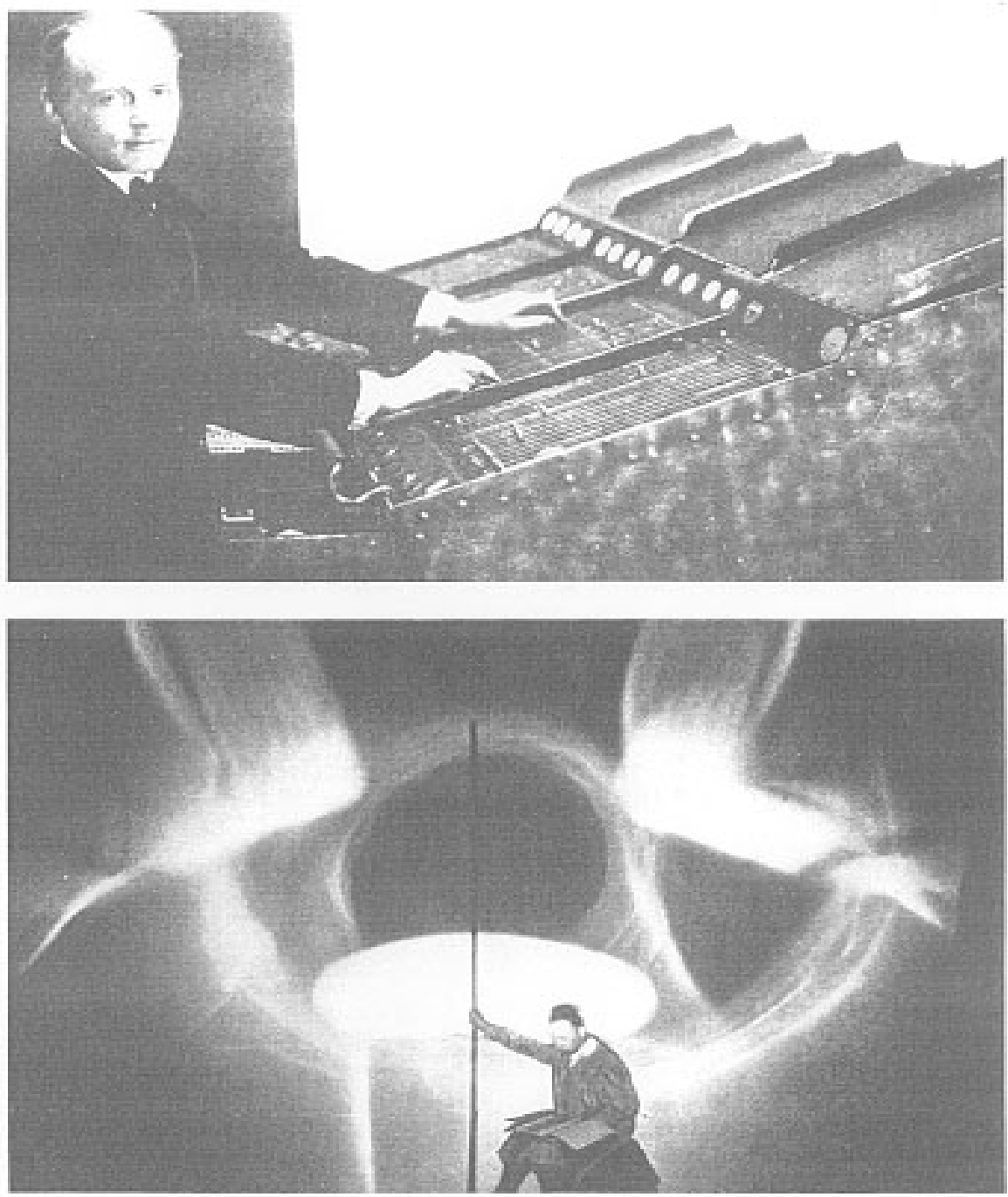

Fig. 8. (a) Thomas Wilfred at the console of his Clavilux (1922). Moving geometric shapes were projected onto a screen as the performer controlled the color intensity of various light sources. An elaborate arrangement of prisms could be twisted or inclined in any plane. (b) Wilfred rehearsing one of his 'Lumia' compositions for the world tour of 1924-1925. He probably used the rod to determine the relative position of his images on the large screen. Critics compared Wilfred's performances of kinetic light to the magnificent display of the Aurora Borealis.

sufficient space to expand and create atmosphere.

According to Luckiesh, others suggested that colors be projected onto loose folds of material that would be "kept moving gently by electric fans placed at a considerable distance" [20]. Had such solutions been adopted, the world premiere of Scriabin's Prometheus with color realization undoubtedly would have received a better press.

In the years following Altschuler's rendition of Prometheus with colored light, a great number of 'color-organs' appeared. It may be difficult to prove a direct link to the color symphony, but Scriabin's composition must have encouraged these developments.

While Castel's eighteenth-century clavecin oculaire and nineteenth-century innovations such as Rimington's Colour-Organ had been conceived to reveal physical connections between light and sound, most instruments built during the early decades of this century were not intended to express direct association. One exception, however, was a device invented in 1912 by an Australian named Alexander Hector. On his instrument yellow corresponded to middle $\mathrm{C}$ - $\mathrm{a}$ pitch associated with red by Rimington 


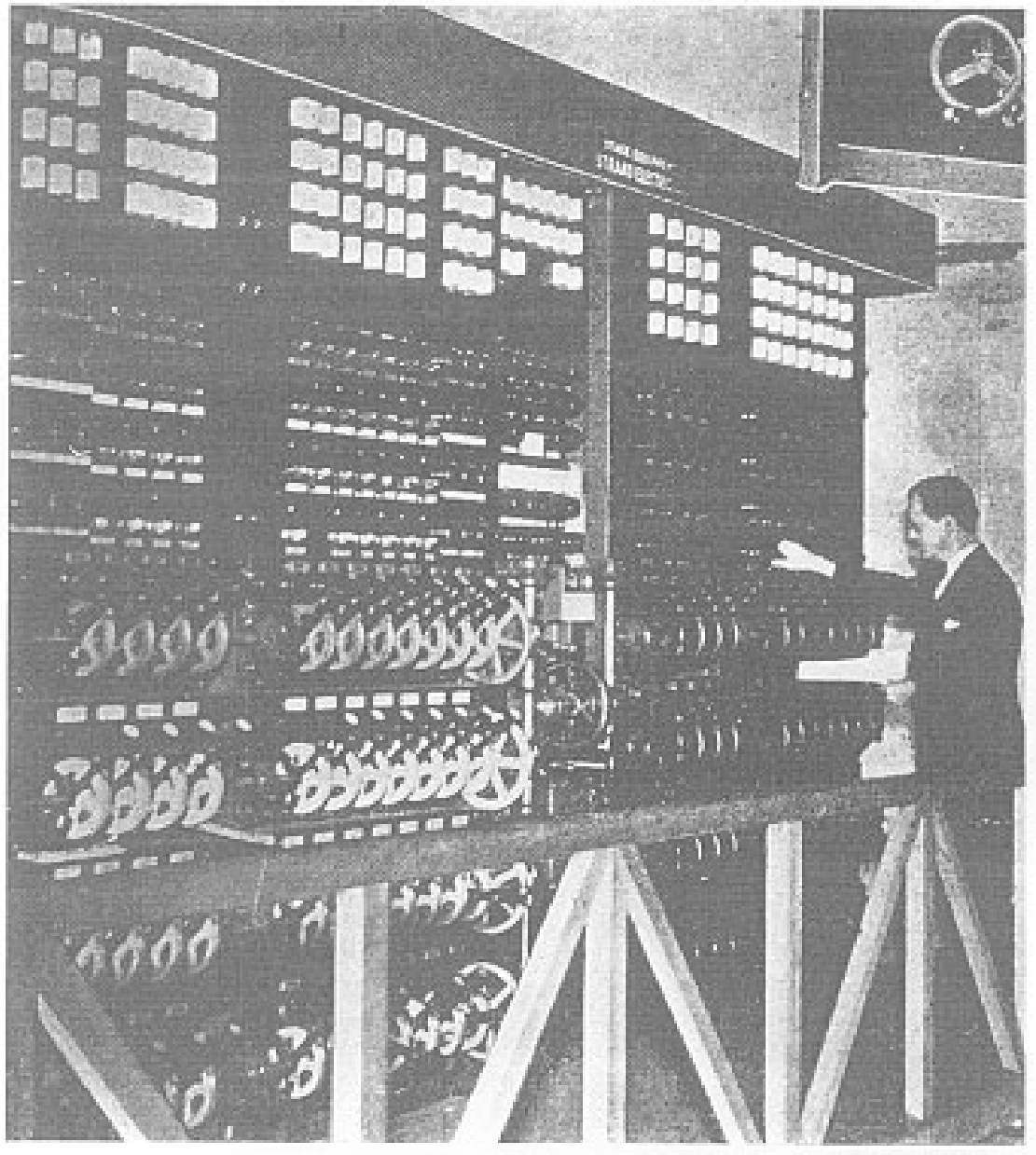

Fig. 9. Frederick Bentham adjusting the Light Console before a performance at the Strand Electric Demonstration Theatre in London (1937). He presented many concerts with orchestral recordings and improvised lighting.

and with blue by Castel. This frequent difference of opinion concerning 'correct' color associations prevented the establishment of a consistent aesthetic for performances of color-music. If one performed the same musical composition on separate instruments (Rimington's and Hector's for example), the resulting translations would yield entirely different colors.

By the early 1920s it became apparent that there was no indisputable correspondence pattern between colors and sounds. For this reason, many predicted the evolution of a new and independent art form-pure light manipulation which had no connection to sound. Experimenters attempted to resolve technical difficulties, and most seem not to have been aware of the work of others in this well-established field. Nearly every color-organ inventor in the nineteenth and early twentieth centuries was under the delusion that he or she was the first to conceive of color-music. Mary Hallock-Greenewalt is perhaps the extreme example. Her book is a self-panegyric in which she claimed in the opening pages, "It is I who have conceived it [color-music], originated it, exploited it, developed it, and patented it" [21]. She concluded (over 400 pages later) that the art she named 'Nourathar' - an arbitrary combination of two Arabic roots - is an aid to better health. Thus her conception of a medicinal use for art anticipated by over half a century the philosophy of todays 'New Age' practitioners.

Hallock-Greenewalt's apparatus for the performance of color-music was named the Sarabet (after her mother, Sara Tabet). In 1919, she demonstrated the machine for the first time [22]. Her elaborate instrument was operated from a small table-like console (Fig. 5a). A sliding rheostat controlled the reflection of seven colored lights onto a monochromatic background. In her concerts of light, Hallock-Greenewalt emphasized variations in luminosity, which she considered as paralleling nuances in musical expression. She treated particular colors as subordinate to diverse intensities of color. A new notational system for performance on the Sarabet was patented by the inventor (see Fig. 5b).

Since 1920 (the year generally considered to mark the birth of kinetic art) many color-projection instruments appeared. For example, in 1920 the English painter Adrian Klein designed a color projector for stage lighting. His instrument, which demonstrated a color theory involving logarithmic division of the visible spectrum, was operated from a two-octave keyboard (Fig. 6). In the same year, Leonard Taylor, another English experimenter, built a device whereby 12 colored lights were activated from a 13note keyboard. Although no relay switches were used, various 'organ stops' controlled individual colors which could then be diluted with a variable-intensity daylight lamp (the thirteenth note). Similar color experiments were carried out between 1920 and 1925 by Achille Ricciardo, who built a colored-light instrument for the Teatro del Colore in Rome, and Richard Lovstrom, who during the same period in the United States patented an apparatus to perform color-music. The Czech artist Zdenek Pasanek worked with a color-keyboard as did Alexander Laszlo, who introduced his device, the Sonchromatoscope (Fig. 7), in 1925 at the Music-Art Festival at Kiel, Germany [23]. Laszlo's book, Die Farblichtmusik, was published the same year. His preludes for piano and colored light employed a special system of notation.

During the period from 1920 to 1925 , Ludwig Hirschfeld-Mack studied at the Weimar Bauhaus. In the summer of 1922, he was among those who were rehearsing one of the shadow plays that were often presented at the Bauhaus. When one of the acetylene bulbs they were using needed replacement, Hirschfeld-Mack accidentally discovered that shadows on a transparent paper screen were doubled. By using acetylene bulbs of different color, 'cold' and 'warm' shadows appeared simultaneously [24]. The principle was refined in subsequent years by using a type of color-organ. This device enabled Hirschfeld-Mack to present reflected light compositions with his own music. The lighting technique was introduced to the public in 1923 at a film matinee at the Berlin Volksbühne and later in Vienna with Fernand Léger's experimental films. After 1960, Hirschfeld-Mack lived in Australia where he continued his activities, dispensing with the keyboard of his apparatus.

\section{WILFRED'S CLAVILUX}

Most famous of the experimental color-instruments was the Clavilux, 
developed in 1922 by Thomas Wilfred at a cost of over $\$ 16,000$. Wilfred completely rejected theories that presumed correspondence between light and sound. Light alone was the principal feature of a new art form he named 'Lumia'. It is true that Van Deering Perrine, the noted American painter and friend of Isadora Duncan, had experimented with various color-instruments around 1912 - and he may have been the first to reject the direct allusion to music-but Wilfred was able to develop the full implications of pure light manipulation. He considered the term 'color-music' a metaphor; yet his art resembled music by including factors of time and rhythm in live performance.

Wilfred first used light in a purely abstract manner, but he later decided form and movement were essential. These he achieved via filters which permitted the projection of moving geometrical shapes onto a screen. Kandinsky's theory that geometrical patterns supplement non-objective use of color possibly influenced Wilfred's work.

Although the first of several instruments had been partially completed in 1919, the Clavilux was introduced to the public on 10 January 1922 in New York after more than a decade of experimentation. Wilfred's main instrument, employing six projectors, was controlled from a 'keyboard' consisting of banks of sliders (Fig. 8a). An elaborate arrangement of prisms could be inclined or twisted in any plane in front of each light source. Color intensity was varied by six separate rheostats which Wilfred operated delicately with his fingers. Selection of geometric patterns was effected via an ingenious system of counterbalanced disks. His shifting light performances have been compared by many to the beautiful display of the Aurora Borealis (see Fig. 8b).

During 1924 and 1925, Wilfred gave an extensive recital tour throughout the United States, Canada and Europe. The late Percival Price once told me about a Clavilux recital (5 January 1925) he had attended in Toronto: "Before the concert there seemed to be an attitude of snobbery toward the new art, but after Wilfred began to perform everyone was spellbound." Nearly all of the published reviews substantiate this conclusion, and the critics' difficulty in finding the right words to describe the effect of the performance is evident. Deems Taylor, for example, wrote:

The fact that Thomas Wilfred's Clavilux is commonly known as the color-organ is not the only reason why a music reviewer should have attended his recital last night in Aeolian Hall. For this new color-art might very aptly be called music for the eye...it is color and light and form and motion, but it is not painting, nor sculpture, nor pantomime. It is difficult to convey in words. Describing the Clavilux to one who has not seen it is like describing an orange to an Esquimo [25].

Wilfred notated his compositions, and they were given opus numbers like musical works. The most enthusiasm seems to have been generated by A Fairy Tale of the Orient (Opus 30). A writer for the Louisville Times (20 November 1924) described the work as "an Arabian night of color, gorgeous, raging, rioting color yet not rioting either...Jewels were poured out of invisible cornucopias; lances of light darted across the screen to penetrate shields of scarlet or green or purple". In the Manchester Guardian (18 May 1925), another reviewer described Wilfred's work as a dream of "some unearthly aquarium where strange creatures float and writhe, and where a vegetation of supernatural loveliness grows visibly before the spectator". From the reports, it seems that Wilfred's art probably surpassed the dramatic effects produced by today's laser performances, especially since his audiences had never witnessed anything like it before. Although most of Wilfred's recitals were presented in complete silence, he also took part in collaborative performances where music was interpreted in colored light. For example in 1926 he collaborated in a presentation of Rimsky-Korsakov's Scheherazade with the Philadelphia orchestra directed by Leopold Stokowski [26].

\section{CONCLUSION}

In the decades following Wilfred's introduction of the Clavilux, many artists experimented with the technique of interpreting music in colored light. George Hall, for example, built a device in the 1930s which he called the Musichrome. It was equipped with eight keys to control two sets of four colors each. In a brochure about his instrument, Hall indicated no set rules to follow when interpreting musical compositions: "The accompanist must follow his own color reactions to the music played. Generally speaking, heavy, loud, thunderous music calls for the use of red, although there are times when an intense blue is desirable" [27].

Frederick Bentham gave performances on a Light Console at the Strand Electric Demonstration Theatre in London shortly before World War II (Fig. 9). At his concerts, he accompanied phonograph recordings of many works including Pictures at an Exhibition, The Firebird, and Prometheus. Describing a presentation of Scriabin's color-symphony on 31 March 1937, Bentham wrote:

The first snag was that I could not feel in accord with the music (I wonder what my present day impression would be) and the second was the difficulty of looking at the score at the same time as keeping my eyes glued to the stage. A colour organist who does not do the latter is equivalent to the musician who plays without listening to himself....After some rehearsal the ordered sequence of colour changes was extracted but...in the end I took the colours as an organist might take a simple theme for improvisation and let myself go to the music [28].

Extensive technical innovation after World War II made possible the permanent installation of a large number of 'color-organs' in theaters and galleries all over the world. These instruments either were operated live or were programmed to present light sculptures. One such work, Wilfred's Lumia Suite (Opus 158), was displayed during the late 1960s in the New York Museum of Modern Art. For two decades (and until recently), the engineer and lighting designer Christian Sidenius gave performances of colored light with music at his private installation in Sandy Hook, Connecticut. His elaborate equipment included stereopticon color-projectors, and he called his concerts "Lumia, the Theatre of Light" in honor of Wilfred's original Lumia Theatre of New York.

Within the past 15 years, the decreasing cost of technology has fired a revival of interest in the practical development of instruments to perform color-music. One result has been that today's consumers of both art and entertainment events have come to expect that their aesthetic experiences will be generated by mixed-media, often including colored light and sound. Annual summer concerts of sound with lighting are presented in Paris; and in the Soviet Union, a large organization under the direction of Bulat Galeyev has constructed color-instruments that have been used to present huge outdoor spectacles of sound and light which are attended by thousands [29]. In the United States and Europe, many color-music concerts of more modest attendance have been presented by various groups. And audiences in our multi-media age have responded enthusiastically to this veritable explosion of activity. Enterprises such as Laser Images Incorporated, for example, have toured colleges in the midwestern United States with portable color instruments for live performances. Repertoires accompanied by colored light have included rock music as well as music by 
Corelli, Strauss, Holst, and Copland. Laser artist Lawrence Goodridge at the Cleveland Institute for the Arts has frequently presented colored-light concerts in silence (like Thomas Wilfred) and has given recitals in collaboration with computer-music composer Jane Brockman. In California, the Laser Arts Society holds monthly meetings to discuss creative applications of lasers for kinetic sculpture. Nor have commercial applications of color-music been neglected. For the 1987-88 holiday season, Macys announced in the New York Times its "gift to New York City - a one-of-a-kind outdoor extravaganza with lasers, lights and holiday music to delight one and all". Inside the store, shoppers could purchase an inexpensive 'color-organ' (the well-known devices are attached to a home stereo and different audio frequencies trigger various colored lights), and then they could step outside to witness the impressive display of lasers with music. Huge colored-laser patterns moving in time to music were projected onto the side of the tall Macys building that occupies an entire city block.

Although experimenters during the past two centuries hardly could have anticipated today's widespread use of laser light in combination with electronic computers, these marvellous inventions are, in some ways, refinements of earlier technological proposals for a viable color-music instrument. Every generation, it seems, must re-discover and re-define the art of color-music for itself. And rarely does there appear to be awareness that previous activity has occurred. The current catalog of one major video company, for example, informs its clients that with their product "a new art form was born. Blending color, music and movement, this new medium is a marriage of sight and sound" [30]. After 200 years, a specific and definitive artistic category in which to place color-music still remains elusive. But today, few would disagree that the kinetic visual arts have genuinely achieved Walter Pater's 'condition of music'.

\section{REFERENCES AND NOTES}

1. Walter Pater, "The School of Giorgione" (1877), in The Renaissance (New York, [n.d.]) p. 111.

2. See, for example, Nicolas Schöffer, "Sonic and Visual Structures", Leonardo 18, No. 2, 59 (1985). Also see the special issue, "Visual Art, Sound, Music and Technology", Leonardo 20, No. 2, 1987.

3. See Hermann Diels, Die Fragmente der Vorsocratiker, Vol. 1, 3rd Ed. (Berlin, 1912) p. 317. The most comprehensive study of the topic is still Adrian Klein's Colour-Music: The Art of Light (London, 1926; 3rd Edition titled Coloured Light, an Art Medium, London, 1937).

4. Goethe considered his most important work to be Zur Farbenlehre (1810); however, little directly concerns sound-color correspondence.

5. See Edward Maryon, Marcotone: The Science of Tone Color (Boston, 1924). In 1943, a lawsuit nearly resulted after Percy Scholes printed in his Oxford Companion that Maryon's color-sound assertions were "without scientific foundation". The present author is currently preparing a study of the Scholes-Maryon controversy.

6. Quoted by E.R. Monteith, "Colour Music...", Proceedings of the Music Association 39 (1912-1913) p. 89. Sound travels in waves through a medium at approximately 1,100 feet per second. Light travels at 186,000 miles per second, requires no medium and exhibits various characteristics when it interacts with matter. These characteristics of light may be described in terms of particles (photons) or in terms of wave motion.

7. Sources available for the present article included the first letter, which appeared in Mercure de France, and Telemann's translation of the second essay, "Beschreibung der Augenorgel oder des Augenclavicimbels, so der beruhmte...Herr Pater Castel erfunden und ins Werck gerichtet hat..." (Hamburg, 1739), reprinted in Lorenz Mizlers musikalische Bibliothek (1742) 2, No. 2, 259-266 (incorrectly paginated; actually pp. 269-276). Other materials concerning Castel's experiments are his Optique des couleurs (1740) and a Journal des travaux pour man clavecin oculaire, which was reported by F.J. Fétis to be in the manuscript collection of the Bibliothèque Royale de Bruxelles. See Biographie universelle des musiciens et bibliographie géneralé de la musique, 2nd Ed. (Paris: Firmin Didot Frères, 1866) p. 206. An anonymous compilation of Castel's essays with biographical information was published in Amsterdam as Esprit, saillies, et singularités du père Castel (1763).

8. See Castel, "Clavecin pour les yeux", Mercure de France (November 1725) pp. 2557-2558.

9. Esprit, saillies, et singularites du père Castel (1763). As quoted by Klein [3], Colour-Music (1926) p. 184.

10. See the reprint of Telemann's article [7] p. 264.

11. "...womit er denn, ohne den Handwerkern Dank zu wissen, beynahe zu Ende gelanget ist." Telemann [7] p. 262.

12. See Albert Wellek, "Farben-harmonie und Farbenklavier. Ihre Entstehungsgeschichte im 18. Jahrhundert", Archiv für die gesamte Psychologie 94, 347-375 (1935) p. 356.

13. As quoted by Wellek [12] p. 369.

14. Frank Popper, Origins and Development of Kinetic Art, Stephan Bann, trans. (Greenwich, CT: Studio Vista, 1968) p. 157.

15. Klein [3] p. 21.

16. Information in Table 2 was adapted from A.W. Rimington, Colour-Music: The Art of Mobile Colour (London, 1911) p. 177. Rimington included vibration frequencies which are omitted in Table 2.

17. For a discussion of how this color-part determines the complete structure of the symphony, see Kenneth Peacock, "Synesthetic Perception: Alexander Scriabin's
Color-Hearing", Music Perception 2, No. 4, 483-506 (1985). A study score of Prometheus, Opus 60, is published by Eulenburg (1980).

18. This performance, given in the Albert Hall on 4 May 1972 by the London Symphony Orchestra under Elyakum Shapirra, was reviewed by Paul Griffiths, The Musical Times 113 (1972) p. 682. For a description of several other performances employing novel approaches to color realization in this work, see Hugh MacDonald, The Musical Times 124 (1983) pp. 600-602.

19. Mathew Luckiesh, Color and Its Applications, 2nd Ed. (New York, 1921) p. 315.

20. Luckiesh [19] p. 321.

21. Mary Hallock-Greenewalt, Nourathar: The Fine Art of Light Color Playing (Philadelphia, 1946) p. 2.

22. In a letter (14 November 1944) to Percy Scholes, Hallock-Greenewalt provided the date of 1919, but she also claimed that the concept originally occurred to her in 1905 . This unpublished letter is now in the National Library of Canada.

23. For more detailed discussions of these and other instruments, see Luckiesh [19]; Klein [3]; Popper [14]; Wellek, "Farbenmusik", Die Musik in Geschichte and Gegenwart. Allgemeine Enzyklopädie der Musik. 3, cots. 1811-1822 (1954); T. Jones, The Art of Light and Color (1972).

24. Ludwig Hirschfeld-Mack, The Bauhaus: An Introductory Survey (1963) p. 6. Also see Hirschfeld-Mack's article, "Reflected-Light Compositions..." (1925), which is reprinted in Bauhaus: Weimar, Dessau, Berlin, Chicago, Hans Wingler, ed. (1969); The Theater of the Bauhaus, Walter Gropius, ed. (1961); Lászlo Moholy-Nagy, Painting, Photography and Film (1969) (originally published in 1925); Bauhaus and Bauhaus People, Neumann, ed. (1970).

25. "The Clavilux", New York World (27 Dec. 1924) p. 26. Also see other reviews of Wilfred's performances; a partial list includes: The Toledo Times (10 Nov. 1924); Columbus Dispatch (12 Nov. 1924); Daily Bulletin [Bloomington, Illinois] (2 Dec. 1924); The Toronto Globe (6 Jan. 1925); Michigan Daily [Ann Arbor, Michigan] (14 Jan. 1925). Popular articles describingthe Clavilux appeared in Vanity Fair (December 1920 and March 1922); Theatre Arts Magazine (January 1922), The New Republic (18 January 1922); Literary Digest (4 February 1922); Shadowland (March. 1922), The Nation (2 August 1922).

26. "Color-Organ with Orchestra", Musical News and Herald (1926) p. 133.

27. Brochure entitled Hall Laboratories for Lighting Research (n.d.) p. 2. A copy is located in the Percy Scholes Archive at the National Library of Canada.

28. Unpublished letter to Percy Scholes dated 4 December 1946. Also of interest is Frederick Bentham's The Art of Stage Lighting, 2nd Ed. (New York, 1976).

29. Bulat Galeyev, ed, Iskusstvo svetiashchikhsia zvukov (Kazan, 1973) pp. 185-188. To date, over 100 articles and books concerning this general topic have been published under Galeyev's direction. [Editor's note: See a related article by Bulat Galeyev in this issue of Leonardo.]

30. Fortuna Records Inc., Catalog of Video Cassette and Video Recordings (1987 distribution). 